\title{
The effect of the incorporation of fluoride into strontium containing bioactive glasses
}

Danujan Sriranganathan $^{\mathrm{a}}$, Xiaojing Chen ${ }^{\star} \mathrm{b}$, Karin A. Hing ${ }^{\mathrm{c}}$, Nasima Kanwal ${ }^{\mathrm{d}}$, Robert G. Hill

aschool of Medicine, Barts and The London School of Medicine and Dentistry, Queen Mary University of London, Turner Street, London E1 2AD, UK, ${ }^{b}$ Dental Physical Sciences, Dental Institute, Barts and The London School of Medicine and Dentistry, Queen Mary University of London, Mile End Road, London E1 4NS, UK.

${ }^{\mathrm{c}}$ School of Engineering and Materials Science, Queen Mary University of London, Mile End Road London E1 4NS, UK.

${ }^{d}$ School of Chemistry, Purdie Building, North Haugh, St Andrews, UK

* Corresponding author, xiaojing.chen@qmul.ac.uk; +44(0)2078825966

\section{Abstract}

Recently, the porous bioactive glasses have attracted a lot of attention for use as scaffolds for tissue engineering bone, such glasses include the high phosphate, strontium containing glass (Stronbone $\mathrm{P}^{\mathrm{TM}}$ ). However, the previous studies suggest that strontium can have a detrimental effect on the ability of apatite-like phase formation of the glass. The previously studied high phosphate all Sr glass showed an unidentified phase rather than an apatite-like phase upon immersion. Octa-calcium phosphate $(\mathrm{OCP})$ is believed to be a precursor phase to apatite, however octastrontium phosphate does not exist. Fluoride is known to knock out the OCP formation and promotes fluorapatite formation. This work presents the incorporation of a small amount of fluoride into calcium/strontium bioactive glasses. Differential 
scanning calorimetry was used to estimate the glass thermal properties. All of the studied glass compositions were subjected to bioactivity studies in Tris buffer $(\mathrm{pH}=7.4)$ for up to 21 days. The initial glasses and the resultant precipitates were analysed using fourier transform infra red spectroscopy, X-ray diffraction and magic angle spinning-nuclear magnetic resonance. The findings showed that all the fluoride containing glasses were amorphous and there was a marked increase in the rate of apatite formation in vitro compared to the equivalent fluoride free glasses, particularly for the all strontium containing glass. This indicates that the presence of fluoride affects the pathway of apatite formation, forming fluorapatite directly instead of via the transformation from OCP to hydroxyapatite. Therefore, fluoride may have potential future clinical applications as an additive to increase apatite formation.

\section{Introduction}

There is considerable interest in developing porous bioactive glasses for the use as scaffolds for tissue engineering bone. A glass suitable for the use as a scaffold should fulfill the following criteria:

1. It should be capable of being sintered by a viscous flow mechanism without crystallisation to give a three dimensional open porous structure with an interconnect size of at least 100 microns to facilitate infiltration by both blood vessels and osteoblasts.

2. It should form an apatite-like layer on its surface.

3. It should not result in a too high $\mathrm{pH}$ rise in vivo.

4. It should actively stimulate the formation of new bone tissue and should osseointegrate. 
5. It should promote angiogenesis.

The strontium containing bioactive glass (SP-Ca/Sr, Stonbone $\mathrm{P}^{\mathrm{TM}}$ ) given in Table 1 exhibits these properties and shows rapid osseointegration and new bone formation in vivo (1). Strontium is known to up-regulate osteoblasts and down-regulate osteoclasts (2). Strontium is also slightly bactericidal (3) (4) and also of relatively high atomic number enabling the placement and resorption of strontium based biomaterials to be visualised using standard X-ray methods. Silicon released from bioactive glass has been shown to stimulate angiogenesis (3). Glass SP-Ca/Sr exhibits a large processing window defined as the onset temperature of crystallisation minus the glass transition temperature $\left(T_{\text {conset }}{ }^{-}{ }_{g}\right)$. This large processing window of over $200^{\circ} \mathrm{C}$ enables the glass particles to be viscous flow sintered without crystallisation occurring. This enables the glass to be formed into porous structures by a variety of routes. The low alkali metal content and high phosphate content reduces the $\mathrm{pH}$ rise, whilst the high phosphate content is known to increase the amount of apatite formed and reduce the time to form apatite (5) (6). However, Sriranganathan et al. (7) found that the introduction of strontium has a detrimental effect on the apatite-like phase formation ability of the glasses.

Sriranganathan et al. investigated the in vitro bioactivity of the glass given in Table 1 and the equivalent glasses containing only calcium and no strontium and only strontium and no calcium (7). The all strontium high phosphate bioactive glass showed the glass to form a new unidentified phase upon immersion in Tris buffer. This new phase is not a strontium apatite $\left(\mathrm{Sr}_{10}\left(\mathrm{PO}_{4}\right)_{6} \mathrm{~F}_{2}\right)$ or Collins salt $\left(\mathrm{Sr}_{6} \mathrm{H}_{3}\left(\mathrm{PO}_{4}\right)_{5} \cdot 2 \mathrm{H}_{2} \mathrm{O}\right)$ and has not been found previously. This phase seems to be a strontium orthophosphate, based on FTIR and ${ }^{31}$ P MAS-NMR data. We have termed this new unidentified phase as "X-phase". In contrast, the related calcium containing 
glass and mixed calcium/strontium glass form an apatite-like phase in both Tris buffer and simulated body fluid. The all strontium glass also forms an apatite-like phase in SBF though its identification is far from conclusive. It is thought that apatite formation goes via the formation of an octa-calcium phosphate precursor phase $\left(\mathrm{Ca}_{8}\left(\mathrm{PO}_{4}\right)_{6} \mathrm{H}_{2} \cdot 5 \mathrm{H}_{2} \mathrm{O}\right)$ if the $\mathrm{pH}<9$ (8) (9). However, octa-strontium phosphate $\left(\mathrm{Sr}_{8}\left(\mathrm{PO}_{4}\right)_{6} \mathrm{H}_{2} \cdot 5 \mathrm{H}_{2} \mathrm{O}\right)$ does not exist (7). Consequently with the strontium bioactive glass it is thought that because the precursor phase can not form, that the formation of an apatite phase is not possible and the X-phase forms instead. In SBF, which contains calcium ions, the strontium containing glass degraded and resulted in octacalcium phosphate formation with possibly a small amount of strontium substituted for calcium in the octa-calcium phosphate lattice. Fluoride is known to knock out the OCP precursor phase and form an apatite directly (10). Brauer et al. (11) and Mneimne et al. (12) showed that fluoride containing bioactive glasses formed fluorapatite and that apatite formation was enhanced by the presence of fluoride. Their results (11) (12) can be explained by fluoride knocking out the precursor OCP phase and forming an apatite directly. The fluoride ion is smaller than hydroxyl ion and therefore the fluoride ion can fit into the space at the center of the $\mathrm{Ca}(\mathrm{II})$ triangle in the apatite crystal lattice and form a more stable fluorapatite compared with hydroxyapatite. There is little direct conclusive evidence for OCP formation with bioactive glasses. This is in part due to OCP and hydroxyapatite being very difficult to distinguish by fourier transform infrared spectroscopy or X-ray powder diffraction. OCP exhibits one characteristic diffraction line at $4.68^{\circ}$ two theta with copper $\mathrm{K}-\alpha \mathrm{X}$ rays. Most studies in the literature do not access this very low two theta range. Furthermore OCP transforms readily to hydroxycarbonated apatite and the $4.68^{\circ}$ two theta spacing corresponds to the large $>2 \mathrm{~nm}$ water layer which is very prone to 
structural disorder and Scherrer line broadening. Fluoride is also known to knock out the formation of Collin's salt and also cause the direct formation of apatite (10). Fluoride has been shown to not only knock out OCP as a precursor phase to apatite, but also inhibits the formation of Collin's salt from strontium and phosphate containing solutions at $\mathrm{pH}=7.0$, resulting in direct formation of a strontium fluoridated apatite (13). Feenstra et al. (13) also found that the fluoridated apatite formed exhibited very strong heterogenous nucleation and its formation exhibited a maximum with fluoride concentration in solution.

Apart from promoting rapid fluorapatite formation, it is also shown that fluoride regulates bone-forming cell activities, promotes osteoblasts-like cell pre-osteogenic, pro-angiogenic responses and bone resorption in vitro (14) (15). Moreover, it is also found that fluoride enables to stimulate osteoblast mitosis and bone formation (16). Those benefits are favourable in the applications of bone substitutes.

Based on these factors it was chosen to investigate bioactive glasses with small fluoride additions and evaluate their degradation and apatite formation abilities in Tris buffer. The hypothesis being that fluoride release from the bioactive glasses will prevent the formation of OCP and other phases like the Collin's salt, the X-phase and form a fluoridated apatite directly, competing with the normal hydroxyapatite formation pathway (17).

\section{Materials and Methods}

The studied glasses were produced by a melt-quenched method in a similar way to a previous paper published by this research group, Sriranganathan et al. (7). The relevant oxides and fluorides were mixed and melted at the appropriate firing temperature shown in Table 1 for 1 hour in a platinum crucible. Different 
temperatures were used to account for the contrasting effects of strontium and fluorine on the melting temperature of the glasses (18). After 1 hour melting, deionised water was used to quench the glass and the resultant coarse powder glass was collected, dried overnight and ground into powder using a Gy-Ro Mill (Glen Creston Ltd, Twickenham UK). An Endecotts EFL 2000/1 automated sieve shaker was used to separate the powder into a fine $(<38 \mu \mathrm{m})$ and coarse powder. A Stanton Redcroft DSC 1500 (Rheometric Scientific, Epsom, UK) was then used to analyse the fine and coarse powder to determine the glass transition temperature $\left(T_{g}\right)$, crystallisation onset temperature ( $T_{\text {conset) }}$, processing window (defined as $T_{\text {conset }}{ }^{-}$ $\left.T_{g}\right)$ and crystallisation peak termperature $\left(T_{c}\right)$ with an accuracy of $\pm 5{ }^{\circ} \mathrm{C}$.

Table 1. Glass composition (mol\%), network connectivity (NC) and glass firing temperature $\left({ }^{\circ} \mathrm{C}\right)$

\begin{tabular}{|c|c|c|c|c|c|c|}
\hline Glass & $\mathbf{S P - C a} / \mathbf{S r}$ & $\mathbf{S P - C a}$ & $\mathbf{S P - S r}$ & $\mathbf{S P F}-\mathrm{Ca} / \mathbf{S r}$ & $\mathbf{S P F}-\mathrm{Ca}$ & $\mathbf{S P F}-\mathrm{Sr}$ \\
\hline $\mathrm{SiO}_{\mathbf{2}}$ & 44.5 & 44.5 & 44.5 & 43.63 & 43.63 & 43.63 \\
\hline $\mathbf{P}_{\mathbf{2}} \mathbf{O}_{\mathbf{5}}$ & 4.5 & 4.5 & 4.5 & 4.41 & 4.41 & 4.41 \\
\hline $\mathrm{Na}_{\mathbf{2}} \mathbf{O}$ & 4 & 4 & 4 & 3.92 & 3.92 & 3.92 \\
\hline $\mathrm{K}_{\mathbf{2}} \mathrm{O}$ & 4 & 4 & 4 & 3.92 & 3.92 & 3.92 \\
\hline $\mathrm{CaO}$ & 17.8 & 35.6 & 0 & 17.45 & 34.90 & 0 \\
\hline $\mathrm{SrO}$ & 17.8 & 0 & 35.6 & 17.45 & 0 & 34.90 \\
\hline $\mathbf{M g O}$ & 7.5 & 7.5 & 7.5 & 7.35 & 7.35 & 7.35 \\
\hline $\mathbf{C a F}$ & 0 & 0 & 0 & 1.96 & 1.96 & 1.96 \\
\hline $\mathbf{N C}$ & 2.31 & 2.31 & 2.31 & 2.2 & 2.2 & 2.2 \\
\hline $\mathbf{T}_{\text {firing }}$ & 1460 & 1450 & 1470 & 1450 & 1440 & 1460 \\
\hline
\end{tabular}

The acellular 'bioactivity' test was conducted at $37^{\circ} \mathrm{C}$ in an incubator with a rotational speed of $60 \mathrm{rpm}$, using $150 \mathrm{mg}$ fine glass powder incubated for periods of $1,3,7,14$ and 21 days in $100 \mathrm{ml}$ of Tris buffer solution (19). After the various time intervals 
passed the solution was filtered and refrigerated prior to analysis. The collected precipitates were dried for 24 hours in an oven at $37^{\circ} \mathrm{C}$ and then investigated for their glass degradation and apatite formation abilities using X-ray Diffraction (XRD), Fourier Transform Infrared (FTIR) and ${ }^{31} \mathrm{P}$ and ${ }^{19} \mathrm{~F}$ Magic Angle Spinning-Nuclear Magnetic Resonance (MAS-NMR).

XRD and FTIR experiments were carried out as previously described (20) using an X'Pert Pro X-ray diffractometer (PANalytical, The Netherlands) and a FTIR Spectroscopy (Spectrum GX, Perkin-Elmer, Cambridge, UK), respectively.

${ }^{31} \mathrm{P}$ and ${ }^{19} \mathrm{~F}$ MAS-NMR spectra were acquired on a Bruker Avance $600 \mathrm{MHz}$ spectrometer at resonance frequencies of $242.9 \mathrm{MHz}$ and $564.7 \mathrm{MHz}$ respectively. ${ }^{31} \mathrm{P}$ MAS-NMR spectra were acquired in a $4 \mathrm{~mm}$ zirconia rotor at a spinning speed of $12 \mathrm{kHz}$, with a recycle delay of $60 \mathrm{~s}$. A total of 32 or 64 scans were used. The chemical shifts were referenced using $85 \% \mathrm{H}_{3} \mathrm{PO}_{4}$ to 0 ppm. ${ }^{19} \mathrm{~F}$ MAS-NMR experiments were carried out in a $2.5 \mathrm{~mm}$ zirconia rotor at a spinning rate of $21 \mathrm{KHz}$. The spectra were recorded after 560 scans and 60 seconds relaxation. Sodium fluoride $1 \mathrm{M}$ aqueous solution producing a sharp signal at $-120 \mathrm{ppm}$ was used as a secondary reference against $\mathrm{CFCl}_{3}$.

\section{Results and Discussion}

All the glasses were optically clear and amorphous by XRD (Figure 1). The maximum in the amorphous scattering shifted to lower two theta values with increasing strontium content as found previously for a number of bioactive glass series where strontium has been substituted for calcium (21) (22) (23) (24) (25) (26). This is consistent with the larger size of the $\mathrm{Sr}^{2+}(1.18 \AA)$ compared to $\mathrm{Ca}^{2+}(1.00 \AA)$ 


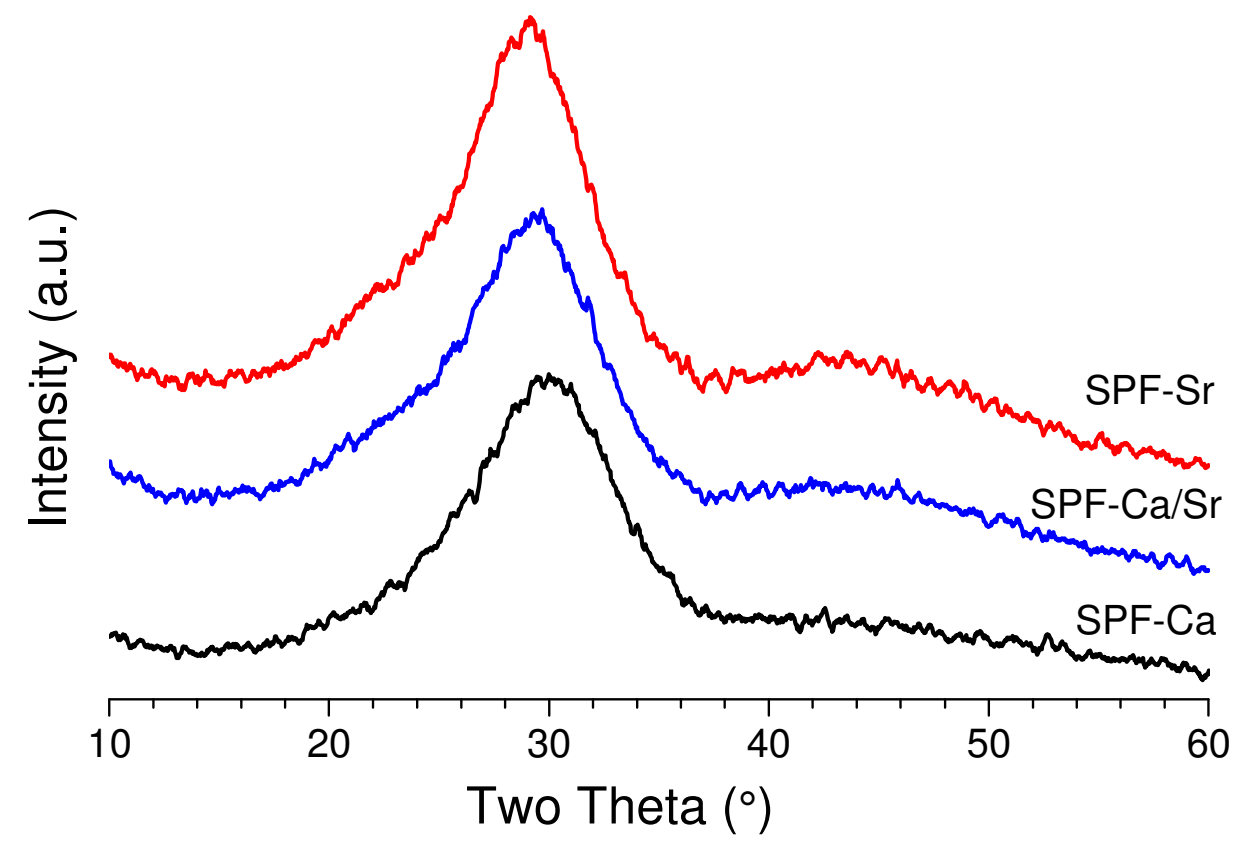

Figure1: XRD patterns of glasses SPF-Ca, SPF-Ca/Sr and SPF-Sr.

Glass thermal properties were analysed by DSC. The obtained $T_{g}$ values, onset temperatures for crystallisation ( $\left.T_{\text {conset }}\right)$ and crystallisation temperatures ( $T_{c 1}$ and $\left.T_{c 2}\right)$ are summarised in Table 2. The $\mathrm{T}_{g}$ values decrease with increasing $\mathrm{Sr}$ content. This matches with the finding by Fredholm et al. (21) and Kie et al. (23) showing that $T_{g}$ decreases with strontium substitution for calcium. The $T_{g}$ values are close to those predicted by Brauer and Hill (28). Incorporation of fluoride decreases the $T_{g}$ by 20 $30^{\circ} \mathrm{C}$ compared to the previously studied glasses (7). The DSC traces of compositions SP-Ca and SPF-Ca are presented as examples in Figure 2. The fluoride containing glasses exhibit an additional small crystallisation exotherm at a lower temperature than the equivalent fluoride free glasses, which is likely to be associated with the fluoride addition and the formation of a fluoride containing crystal phase. The first peak crystallisation temperature also reduces with $\mathrm{Sr}$ content in a 
similar fashion to $T_{g}$. XRD results of heat-treated fluoride containing glasses from Chen et al. (29) showed the first crystallisation process to correspond to the formation of a fluorapatite, which is not surprising given the low alkali metal content. The processing window defined as the onset temperature for crystallisation minus the $\mathrm{T}_{\mathrm{g}}(30)$ reduces on incorporating $\mathrm{CaF}_{2}$, but is still over $120^{\circ} \mathrm{C}$. A large processing window facilitates viscous flow sintering well above the $T_{g}$ without crystallisation occurring and is important for the synthesis of porous scaffolds. The large reduction in the heat flux after $T_{g}$ with the fine powder $(<38 \mu \mathrm{m})$ did not occur with 1-2mm glass particles. This change is associated with the viscous flow sintering of the fine glass particles and a change in the heat flux associated with sintering. This change in the heat flux is much greater in the fluoride free glass than in the fluoride containing glass, which again indicates that the fluoride containing glass does not sinter so readily as the equivalent fluoride free glass. Similar behaviours were found for the compositions of SPF-Ca/Sr and SPF-Sr.

Table 2. $T_{g}$ values, onset temperatures for crystallisation ( $\left.T_{\text {conset }}\right)$ and crystallisation temperatures $T_{c 1}$ and $T_{c 2}$ for glasses.

\begin{tabular}{|c|c|c|c|c|c|}
\hline & $\mathrm{T}_{\mathrm{g}}\left({ }^{\circ} \mathrm{C}\right)$ & $\mathrm{T}_{\text {conset }}\left({ }^{\circ} \mathrm{C}\right)$ & $\mathrm{T}_{\mathrm{c} 1}\left({ }^{\circ} \mathrm{C}\right)$ & $\mathrm{T}_{\mathrm{c} 2}\left({ }^{\circ} \mathrm{C}\right)$ & $\mathrm{T}_{\text {conset }} \mathrm{T}_{\mathrm{g}}\left({ }^{\circ} \mathrm{C}\right)$ \\
\hline SPF-Ca $<38 \mu \mathrm{m}$ & 596 & 717 & 801 & 874 & 121 \\
\hline SPF-Ca Frit & 591 & 782 & 819 & 926 & 191 \\
\hline SPF-Ca/Sr $<38 \mu \mathrm{m}$ & 570 & 687 & 770 & 899 & 117 \\
\hline SPF-Ca/Sr Frit & 569 & 771 & 811 & 914 weak & 202 \\
\hline SPF-Sr $<38 \mu \mathrm{m}$ & 562 & 703 & 740 & 824 & 141 \\
\hline SPF-Sr Frit & 559 & 708 & 743 & 906 & 184 \\
\hline
\end{tabular}




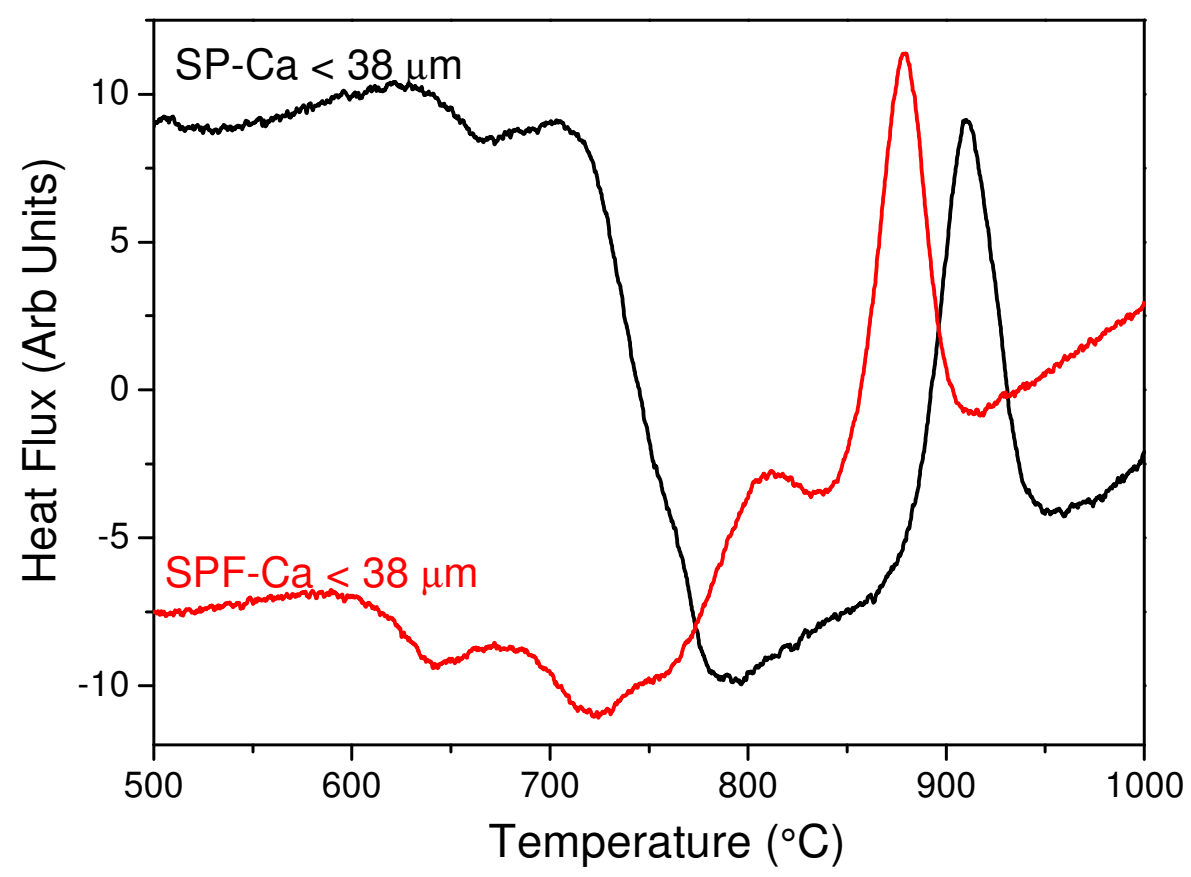

Figure 2: DSC traces for glass powder $(<38 \mu \mathrm{m})$ of the all calcium glasses with and without fluoride (SPF-Ca and SP-Ca).

The XRD patterns of the all Ca glass (SPF-Ca) after immersion in Tris buffer for periods up to 14 days are shown in Figure 3a. Diffraction peaks at approximately 25.8 and $30-33^{\circ}$ two theta corresponding to the principal diffraction lines for fluorapatite are present after 1 day. There is also the loss of the original amorphous scattering from the glass and the development of a broad peak at $20-23^{\circ}$ two theta corresponding to silica-gel formation. Here, no significant difference in the peak intensity with increasing in immersion time up to 14 days was noticed, indicating rapid apatite formation. Similar results were found for the mixed glass (SPF-Ca/Sr) and the all Sr glass (SPF-Sr, in Figure 3b), but the strontium substituted fluorapatite did not form until 7 days in the latter. The apatite diffraction lines intensified with an increase in immersion time up to 14 days, suggesting the formation of a more ordered apatite with time. 
(a)

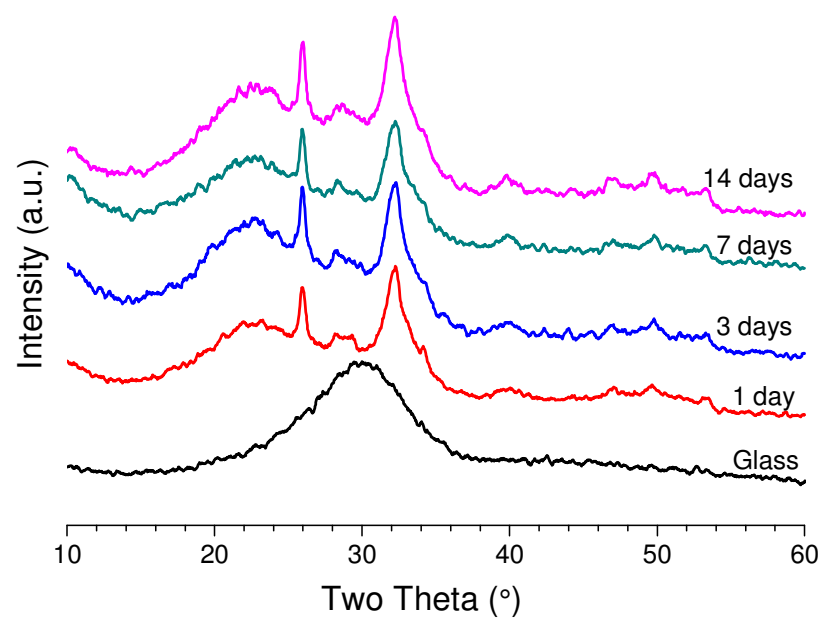

(b)

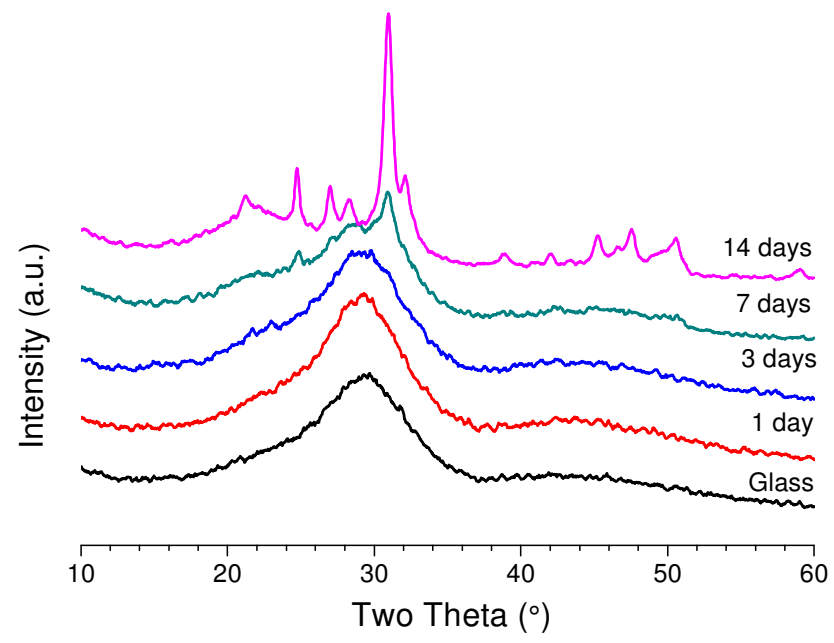

Figure 3: XRD patterns of glasses (a) SPF-Ca and (b) SPF-Sr after immersion in Tris Buffer for $0,1,3,7$ and 14 days.

Figure 4 compares the XRD patterns of the studied glasses after 7 days immersion in Tris buffer. It is clear that the all Ca glass shows the most pronounced apatite diffraction lines, matching that of $\mathrm{Ca}_{10}\left(\mathrm{PO}_{4}\right)_{6} \mathrm{~F}_{2}(00-034-0011)$. On incorporating Sr, the diffraction lines are less distinct and the XRD patterns are composed of both residual glass and the formed apatite. This is in agreement with previous study of the substitution of $\mathrm{Sr}$ with $\mathrm{Ca}$ in fluoride free glasses by Sriranganathan et al. (7), which shows that the introduction of Sr retards glass degradation and apatite formation. In the case of the all Sr glass, the developed diffraction lines largely match the principal diffraction lines for $\mathrm{Sr}_{10}\left(\mathrm{PO}_{4}\right)_{6} \mathrm{~F}_{2}(00-050-1744)$. Taking a careful look at the patterns, the diffraction peaks shift to slightly lower two theta values with increasing strontium content in the glass. Here, the $\mathrm{Ca}_{10}\left(\mathrm{PO}_{4}\right)_{6} \mathrm{~F}_{2}$ is expected to be formed in glass SPFCa, while the mixed $(\mathrm{Ca} / \mathrm{Sr})_{10}\left(\mathrm{PO}_{4}\right)_{6} \mathrm{~F}_{2}$ and $\mathrm{Sr}_{10}\left(\mathrm{PO}_{4}\right)_{6} \mathrm{~F}_{2}$ phases are expected to form in SPF-Ca/Sr and SPF-Sr respectively. 


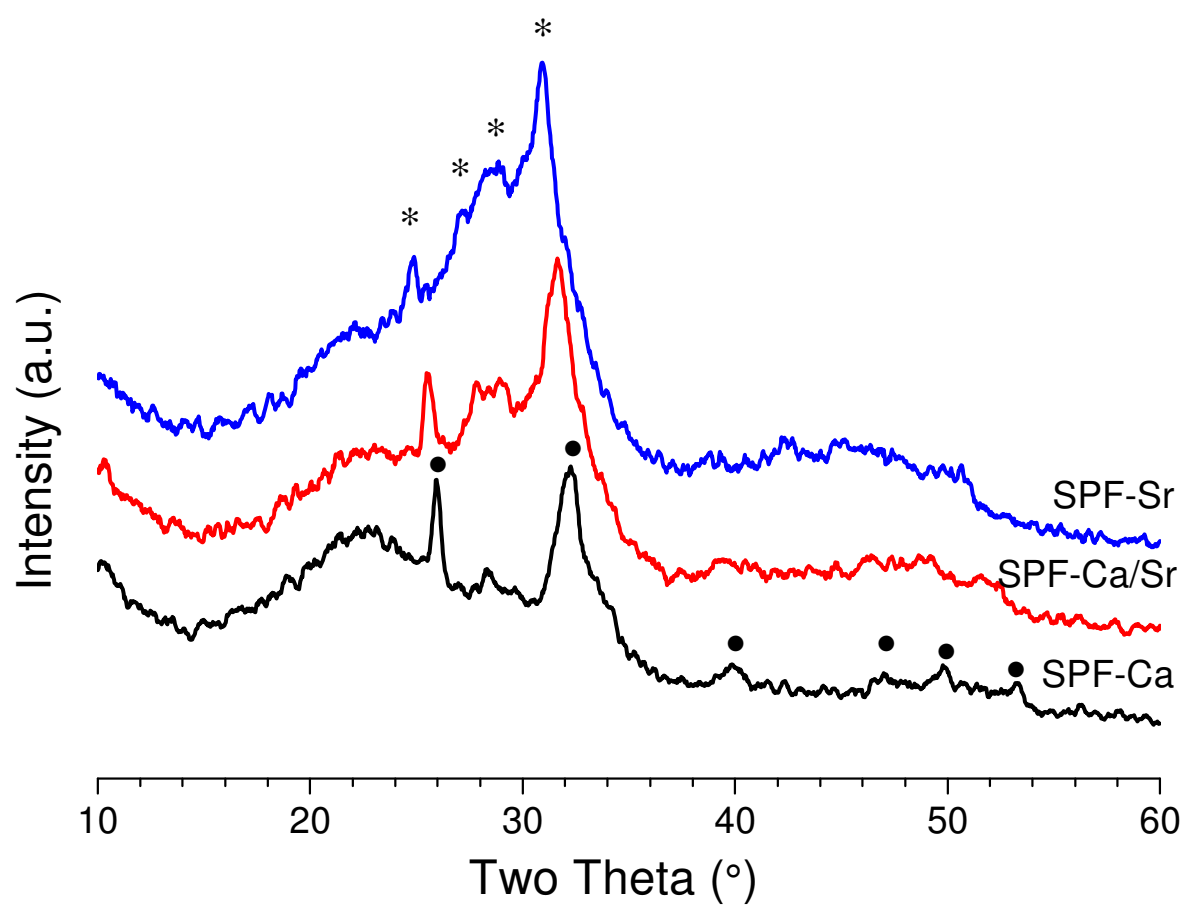

Figure 4: Comparison of XRD patterns after 7 days immersion in Tris Buffer for

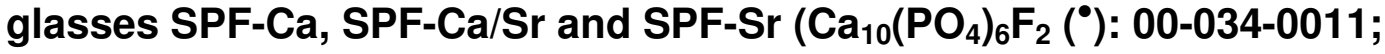
$\mathrm{Sr}_{10}\left(\mathrm{PO}_{4}\right)_{6} \mathrm{~F}_{2}\left(^{*}\right):$ 00-050-1744).

Figure 5 compares the diffraction patterns obtained for the all strontium glass with and without fluoride after 14 days immersion. In the absence of fluoride apatite does not form and the unidentified highly crystalline strontium orthophosphate phase forms (5). In contrast, with the small addition of fluoride the diffraction pattern corresponds to that of strontium fluorapatite. 


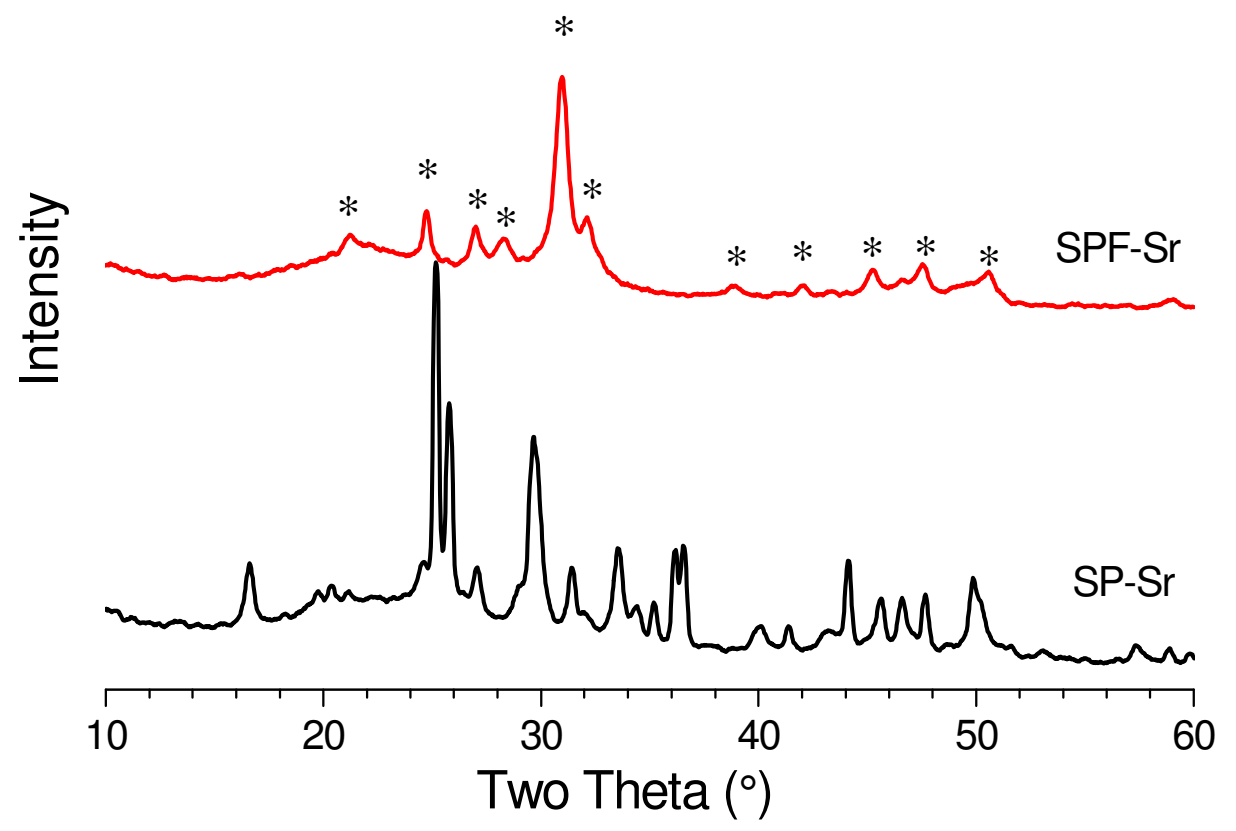

Figure 5: Comparison of XRD patterns after immersion in Tris Buffer for SPFSr and SP-Sr in Tris 14 days. The FTIR spectra of all $\mathrm{Ca}$ and all Sr glasses before and after immersion in Tris buffer are shown in Figure $6 \mathrm{a}$ and 6b. For the initial glasses, there is a broad feature corresponding to the $\mathrm{P}-\mathrm{O}$ bending mode and also a $\mathrm{Si}-\mathrm{O}-\mathrm{Si}$ bending vibration in the region $500-600 \mathrm{~cm}^{-1}$ (31) (21). The band around $840 \mathrm{~cm}^{-1}$ in the glass spectra is due to $\mathrm{Si}-\mathrm{O}-2 \mathrm{NBO}$ functional group $\left(\mathrm{Q}^{2}\right)(21)$. The dominant bands at approximately 910 and $990 \mathrm{~cm}^{-1}$ are attributed to $\mathrm{Si}-\mathrm{O}\left(\mathrm{Q}^{2}\right)$ and Si-O-Si stretching vibrations respectively (31) (21).

(a)

(b) 

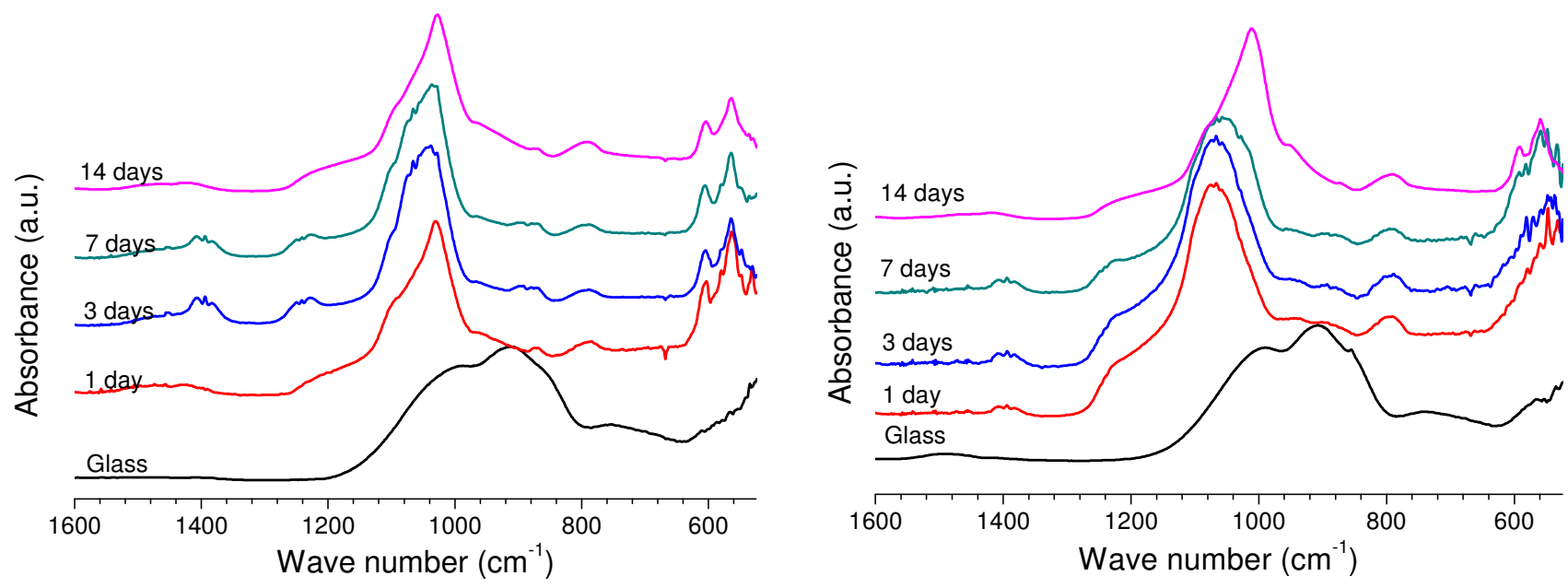

Figure 6: FTIR spectra of (a) SPF-Ca and (b) SPF-Sr after immersion in Tris Buffer for 0, 1,3,7 and 14 days.

Upon immersion in Tris buffer, the glass degradation leads to a reduction in the intensity of $Q^{2}$ vibration band at $910 \mathrm{~cm}^{-1}$. In addition, the typical apatite split peaks at 560 and $605 \mathrm{~cm}^{-1}$ appear corresponding to a crystalline orthophosphate or apatite that is seen in the XRD after 1 day immersion for the all Ca glass and 7 days for the mixed glass and the all Sr glass, indicating rapid apatite formation (32).

Figure $7(a)$ displays the ${ }^{31} \mathrm{P}$ MAS-NMR spectra of the as-quenched fluoride containing glasses. All the spectra exhibit a broad peak corresponding to amorphous sodium/calcium/strontium orthophosphate. With the substitution of $\mathrm{Ca}$ with $\mathrm{Sr}$, the chemical shifts increase progressively from $3.5 \mathrm{ppm}$ to $4.4 \mathrm{ppm}$, attributed to the lower charge-to-size ratio of the strontium cation relative to calcium (23). Figure 7(b) presents the ${ }^{31} \mathrm{P}$ NMR spectra of SPF-Ca immersed in Tris up to 21 days. It is interesting to note that after immersion the isotopic chemical shift of the spectra shift towards $2.8 \mathrm{ppm}$ as a result of forming calcium orthophosphate and the linewidth of the spectra reduced gradually with an increase in immersion time indicating rapid (1 day) apatite-like phase formation and the formation of a more ordered apatite with 
increasing in immersion time. Similar changes are noticed in the Figure 7(c) and (d) for SPF-Ca/Sr and SPF-Sr. Moreover, the linewidth of the all calcium glass after a period of immersion are much narrower than the equivalent Sr containing glasses, confirming a more rapid apatite formation in the glass with the absence of Sr. This is in agreement with previous studies by Sriranganathan et al. (7) revealing that $\mathrm{Sr}$ retards apatite-like phase formation.

(a)

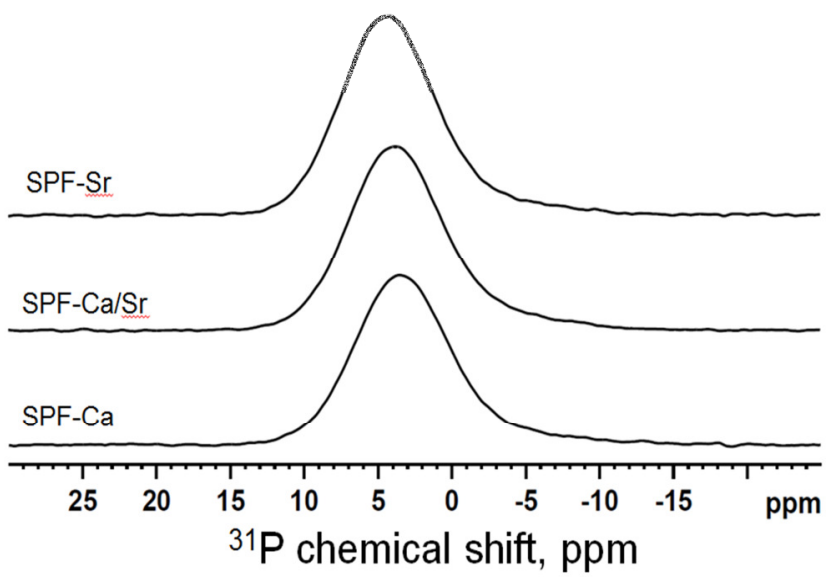

(c)

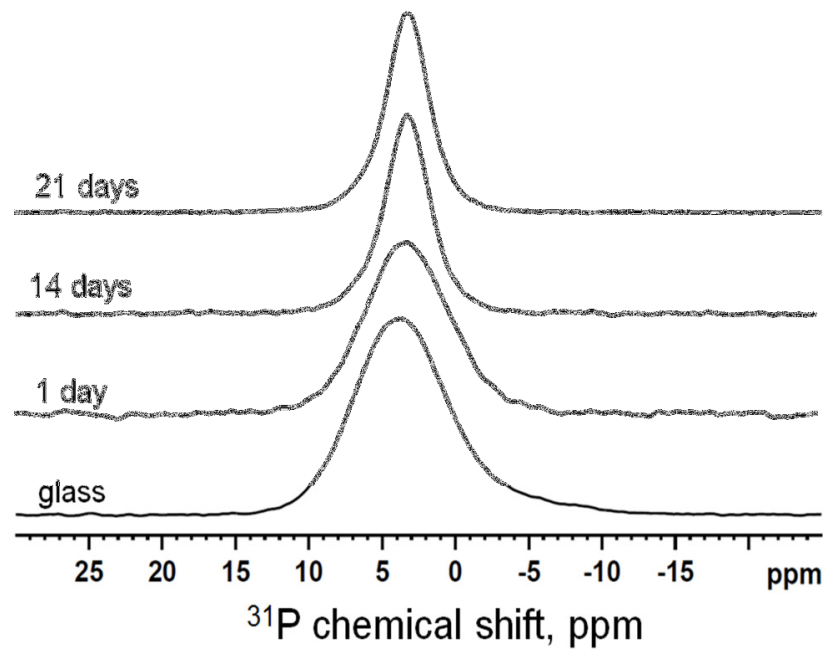

(b)

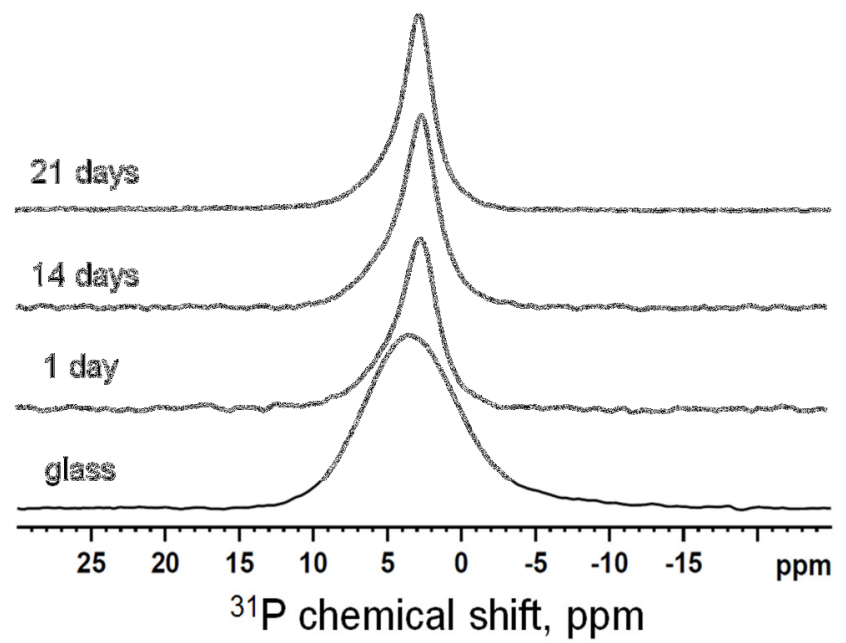

(d)

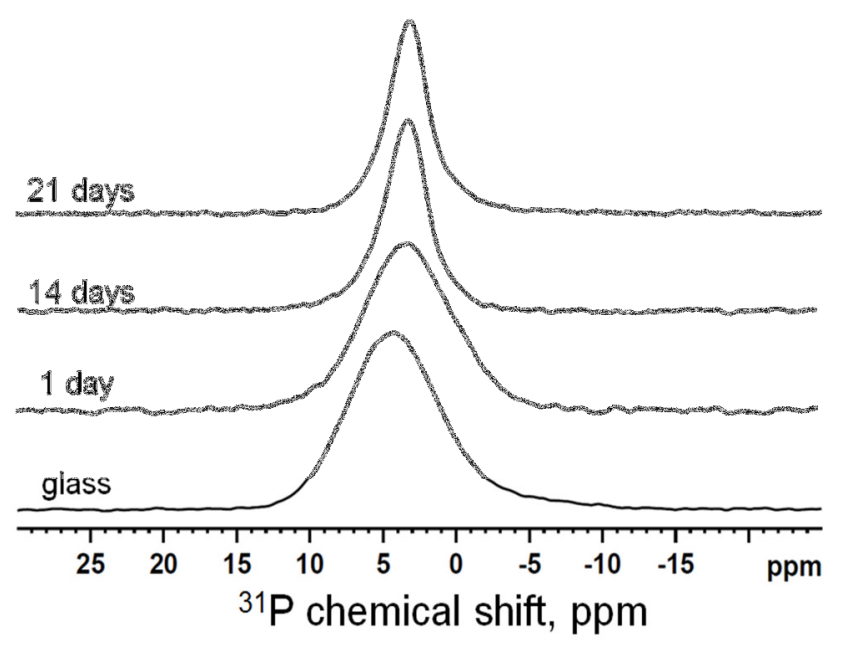

Figure 7: ${ }^{31} \mathrm{P}$ MAS-NMR spectra of (a) the fluoride containing glasses; (b) SPFCa glass immersed in Tris up to 21 days; (c) SPF-Ca/Sr glass immersed in Tris up to 21 days; (d) SPF-Sr glass immersed in Tris up to 21 days 
Figure 8 show the ${ }^{19} \mathrm{~F}$ MAS-NMR spectra of the glasses and the glasses after 21 days immersion in Tris buffer solution. The three glass spectra show the presence of a series of broad overlapping peaks corresponding to mixed F-M(n) species, where $\mathrm{M}$ is largely $\mathrm{Ca} / \mathrm{Sr}$ and $\mathrm{Na}$. Brauer et al. (28) showed that $\mathrm{F}$ was complexed by $\mathrm{Ca}$ and $\mathrm{Na}$ with mixed $\mathrm{F}-\mathrm{Ca} / \mathrm{Na}(\mathrm{n})$ species present, whilst Chen et al. (29) showed that $\mathrm{F}-\mathrm{Ca}(\mathrm{n})$ species were present in sodium-free fluoride containing glasses. It is clear that the spectra move to a higher chemical shift with increasing Sr content. The all Ca glass exhibits a peak at about -100 ppm while the all Sr glass one at - 83.2 ppm and the mixed one sits in between. This is due to the fact that $\mathrm{Sr}^{2+}$ cation is larger than the $\mathrm{Ca}^{2+}$ cation and the different shieling effects of two cations. After 21 days immersion, the broad peak from the original glass disappeared and new peaks emerged. In the case of the all Ca glass, an asymmetric peak develops at -102.5 ppm assigned to the $\mathrm{F}-\mathrm{Ca}(3)$ site in calcium fluroapatite (29), while the broad shoulder at $-90 \mathrm{ppm}$ could be indicative of the existence of residual glass, but is more likely an interstitial fluoride ion associated with B type carbonate substitution $\left(\mathrm{CO}_{3} \mathrm{~F}\right)^{3-}(33)$. In the case of the all Sr glass, two peaks appear at about $-67 \mathrm{ppm}$, corresponding to $\mathrm{F}-\mathrm{Sr}(3)$ site in strontium fluroapatite and $-85 \mathrm{ppm}$ which probably again corresponds to an interstitial fluoride ion associated with B type carbonate substitution (33). For the mixed $\mathrm{Ca}$ and Sr glass, multiple peaks are present that are not fully resolved at $-75,-91.8$ and -108 ppm after 21 days immersion. These peaks correspond to the presence of mixed sites, such as F-CaSr(2), (predicted at -79ppm) $\mathrm{F}-\mathrm{Ca}(2) \mathrm{Sr}$ (predicted at $-91 \mathrm{ppm}$ ) species in mixed calcium/strontium fluroapatites and $\mathrm{F}-\mathrm{Ca}(3)$ species. This is in good agreement with the previous study by Hill et al. (34) which showed that upon heat treatment, that a calcium glass crystalised to calcium fluroapatite while the fully strontium substituted glass crystallised to 
strontium fluoapatite and the mixed calcium strontium glass crystallised to mixed calcium/strontium fluroapatites.

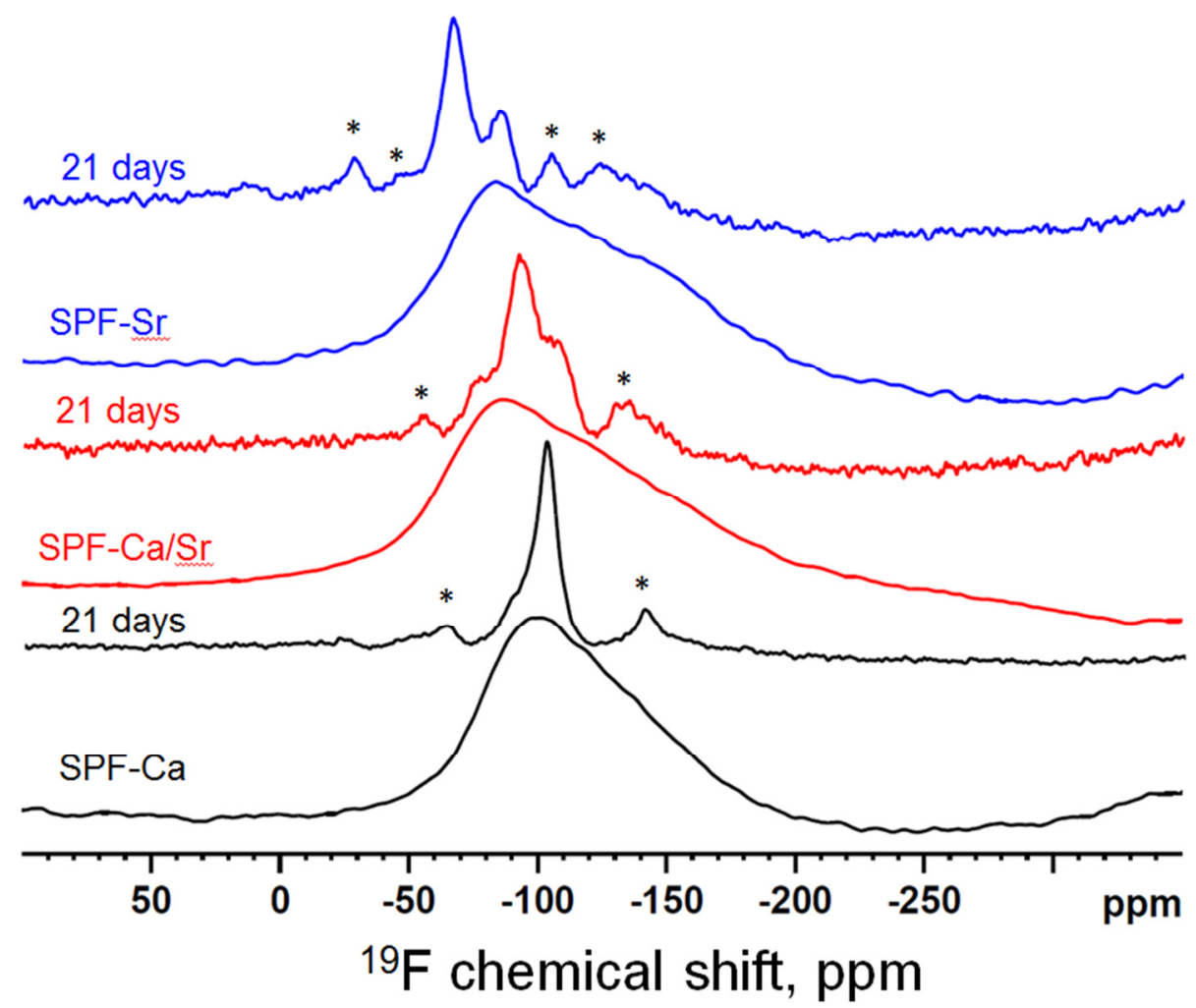

Figure $8 .{ }^{19} \mathrm{~F}$ MAS-NMR spectra of the as-quenched fluoride containing glasses and after immersion in Tris for $\mathbf{2 1}$ days, the asterisks represent the spinning side bands.

The XRD, FTIR, ${ }^{31} \mathrm{P}$ and ${ }^{19} \mathrm{~F}$ NMR consistently reveal that the introduction of fluoride into calcium and strontium glasses promotes and speeds up the apatite formation significantly compared with the equivalent fluoride free glasses studied by Sriranganathan et al. (7). It is interesting and important to note that the incorporation of fluoride into the calcium free glass SP-Sr knocks out the formation of the $\mathrm{X}$ phase. In this glass it appears as if 2 mol\% $\mathrm{CaF}_{2}$ is sufficient to inhibit the formation of the $\mathrm{X}$ phase and promote the formation of fluorapatite. This is significant as the retardation of apatite formation caused by a high concentration of strontium is a limiting factor in 
its use in commercial bioactive glass formulations. Based on this in vitro study in Tris, fluoride is found to act independently of strontium to increase apatite formation. Although, the presence of fluoride also has some undesirable effects such as reducing the size of the sintering window, which will impede sintering and the synthesis of amorphous porous scaffolds. However, the sintering window is still over $100{ }^{\circ} \mathrm{C}$.

It is important to note that in vivo there will always be a continuous turnover of calcium rich body fluids and a readily available supply of calcium ions, which will favour apatite formation. This effect is not included in the present study nor is it included in the widely used Simulated Body Fluid test developed by Kokubo.

\section{Conclusion}

The incorporation of fluoride leads to a reduction in $T_{g}, T_{c}$ and the sintering window. In this in vitro study small additions of fluoride act independently to increase apatite formation with both strontium free and strontium containing bioactive glasses, counteracting the negative effects that strontium has on apatite formation. The effect of fluoride is most pronounced in the all strontium glass, which formed a strontium fluorapatite. The fact that fluoride promotes apatite formation in all the glasses and especially the all strontium one supports the hypothesis that apatite formation occurs via an OCP precursor phase in bioactive glasses and that strontium suppresses the formation of apatite, since octa-strontium phosphate cannot form. Moreover, the incorporation of fluoride knocks out the formation of OCP and results in the direct formation of fluorapatite. As a consequence of this, fluoride can be used as a promising additive to increase the apatite formation with bioactive glasses for tissue 
engineered scaffolds and this is particularly beneficial where it is undesirable for the $\mathrm{pH}$ to increase to high values.

\section{References}

1. Tang HM. Porous Melt-Derived Bioactive Glass Scaffolds for Bone Regeneration via Gel-Cast Foaming. PhD Thesis. London: Imperial College London, Materials; 2014.

2. Gentleman E, Fredholm Y, Jell G, Lotfibakhshaiesh N, O'Donnell M, Hill R, et al. The effects of strontium-substituted bioactive glasses on osteoblasts and osteoclasts in vitro. Biomaterials. 2010 May; 31(14): p. 3949-3956.

3. Brauer D, Karpukhina N, Kedia G, Bhat A, Law R, Radecka I, et al. Bactericidal strontium-releasing injectable bone cements based on bioactive glasses. Journal of the Royal Society Interface. 2013 January; 10(78): p. 1-8.

4. Liu J, Rawlinson S, Hill R, Fortune F. Strontium-substituted bioactive glasses in vitro osteogenic and antibacterial effects. Dental Materials. 2016 March; 32(3): p. 412-422.

5. O'Donnell M, Watts S, Hill R, Law R. The effect of phosphate content on the bioactivity of sodalime-phosphosilicate glasses. Journal of Materials Science: Materials in Medicine. 2009 August; 20(8): p. 1611-1618.

6. Edén M. The split network analysis for exploring composition-structure correlations in multicomponent glasses: I. Rationalizing bioactivity-composition trends of bioglasses. Journal of NonCrystalline Solids. 2011 March; 357(6): p. 1595-1602.

7. Sriranganathan D, Kanwal N, Hing K, Hill R. Strontium substituted bioactive glasses for tissue engineered scaffolds: the importance of octacalcium phosphate. Journal of materials science. Materials in medicine. 2016 February; 27(2): p. 1-10.

8. Brown W. Octacalcium phosphate and hydroxyapatite crystal structure. Nature. 1962; 196(4859): p. 1048-1050.

9. Brown W, Eidelman N, Tomazic B. Octacalcium phosphate as a precursor in biomineral formation. Advances in dental research. 1987 December; 1(2): p. 306-313.

10. Gillam D. Dentine Hypersensitivity: Advances in Diagnosis, Management, and Treatment. 1st ed. Gillam D, editor.: Springer; 2015.

11. Brauer D, Karpukhina N, O'Donnell M, Law R, Hill R. Fluoride containing bioactive glasses: Effect of glass design and structure on degradation, $\mathrm{pH}$ and apatite formati.on in simulated body fluid. Acta Biomaterialia. 2010 August; 6(8): p. 3275-3282. 
12. Mneimne M, Hill R, Bushby A, Brauer D. High phosphate content significantly increases apatite formation of fluoride-containing bioactive glasses. Acta Biomaterialia. 2011 April; 7(4): p. 18271834.

13. Feenstra TP, Van Straten HA, De Bruyn PL. Formation of strontium phosphates in supersaturated solutions. Journal of Colloid and Interface Science. 1981 March; 80(1): p. 255-270.

14. Huo L, Liu K, Pei J, Yang Y, Ye Y, Liu Y, et al. Flouride Promotes Viability and Differentiation of Osteoblast-Like Saos-2 Cells Via BMP/Smads Signaling Pathway. Biological Trace Element Research. 2013 August; 155(1): p. 142-149.

15. Liu J, Rawlinson S, RG H, Fortune F. Fluoride incorporation in high phosphate containing bioactive glasses and in vitro osteogenic, angiogenic and antibacterial effects. Dental Materials. 2016 October; 32(10): p. e221-e237.

16. Guida A, Hill R, Towler M, Eramo S. Fluoride release from model glass ionomer cements. Journal of materials science. Materials in medicine. 2002 July; 13(7): p. 645-649.

17. Kim CY, Clark AE, Hench LL. Early stages of calcium-phosphate layer formation in bioglasses. Journal of Non-Crystalline Solids. 1989 December; 113(2-3): p. 195-202.

18. Bachar A, Mercier C, Tricoteaux A, Hampshire S, Leriche A, Follet C. Effect of nitrogen and fluorine on mechanical properties and bioactivity in two series of bioactive glasses. Journal of the mechanical behaviour of biomedical materials. 2013 July; 23: p. 133-148.

19. Campion C, Ball S, Clarke D, Hing KA. Microstructure and chemistry affects apatite nucleation on calcium phosphate bone graft substitutes. Journal of Materials Science: Materials in Medicine. 2013 March; 24(3): p. 597-610.

20. Shah F, Brauer D, Wilson R, Hill R, Hing K. Influence of cell culture medium composition on in vitro dissolution behaviour of a fluoride-containing bioactive glass. J Biomed Mater Res A. 2014; 102(3): p. 647-654.

21. Yann C. Fredholm NKRVLRGH. Strontium containing bioactive glasses: Glass structure and physical properties. Journal of Non-Crystalline Solids. 2010 October; 356(44-49): p. 2546-2551.

22. Xiang Y, Du J. Effect of Strontium Substitution on the Structure of 4555 Bioglasses. Chemistry of Materials. 2011 May; 23(11): p. 2703-2717.

23. Fujikura K, Karpukhina N, Kasuga T, Brauer D, Hill R, Law R. Influence of strontium substitution on structure and crystallisation of Bioglass ${ }^{\circledR}$ 45S5. Journal of Materials Chemistry. 2012 March; 22(15): p. 7395-7402.

24. Martin R, Twyman H, Rees G, Barny E, Moss R, Smith J, et al. An examination of calcium and strontium site distribution in bioactive glasses through isomorphic neutron diffraction, $\mathrm{X}$-ray diffraction EXAFS and multinuclear solid state NMR. Journal of Materials Chemistry. 2012 
September; 22(41): p. 22212-22223.

25. Lotfibakhshaiesh N, Brauer D, Hill R. Bioactive glass engineered coatings for Ti6Al4V alloys: Influence of Strontium substitution for calcium on sintering behaviour. Journal of Non Crystal Solids. 2010 October; 356(44-49): p. 2583-2590.

26. Wu ZY, Hill RG, Yue S, Nightingale D, Lee PD, Jones JR. Melt-derived bioactive glass scaffolds produced by a gel-cast foaming technique. Acta Biomaterialia. 2011 April; 7(4): p. 1807-1816.

27. Shannon RD. Revised effective ionic radii and systematic studies of interatomic distances in halides and chalcogenides. Acta Crystallographica. 1976 September; 32(5): p. 751-767.

28. Brauer DS, Karpukhina N, Law RV, Hill RG. Structure of fluoride-containing bioactive glasses. Journal of Materials Chemistry. 2009 June; 19(31): p. 5629-5636.

29. Chen X, Chen X, Brauer DS, Wilson RM, Hill RG, Karpukhina N. Novel alkali free bioactive fluorapatite glass ceramics. Journal of Non-Crystalline Solids. 2014 October; 402: p. 172-177.

30. Hill R, Brauer DS. Predicting the glass transition temperature of bioactive glasses from their molecular chemical composition. Acta Biomaterialia. 2011 October; 7(10): p. 3601-3605.

31. Hill RG, Brauer DS. Predicting the bioactivity of glasses using the network connectivity or split network models. Journal of Non-Crystalline Solids. 2011 December; 357(24): p. 3884-3887.

32. Penel G, Leroy G, Rey C, Sombret B, Huvenne J, Bres E. Infrared and Raman microspectrometry study of fluor-fluor-hydroxy and hydroxy-apatite powders. Journal of Materials Science: Materials in Medicine. 1997 May; 8(5): p. 271-276.

33. Yi H, Balan E, Gervais C, Segalen L, Fayon F, Roche D, et al. A carbonate-fluoride defect model for carbonate-rich fluorapatite. American Mineralogist. 2013 May; 98(5-6): p. 1066-1069.

34. Hill RG, Stamboulis A, Law RV, Clifford A, Towler MR, Crowley C. The influence of strontium substitution in fluorapatite glasses and glass-ceramics. Journal of Non-Crystal Solids. 2094 May; 336(3): p. 223-229. 